[Agr. Biol. Chem., Vol. 28, No. 1, p. 1 4, 1964]

\title{
The Aroma Constituents of "KOGYOKU" Apple
}

\author{
By Kiichi Nishimura and Yoshio Hirose \\ The Institute of Food Chemistry, Osaka \\ Received May 29, 1963
}

\begin{abstract}
Investigation was carried out about the aroma constituents of "KOGYOKU" apples. After ethereal extraction and fractional distillation, $23 \mathrm{~g}$ of neutral oil was obtained from $21.7 \mathrm{~kg}$ of commercial natural flavour essence. Carbonyl compounds remained mostly in aqueous phase. The yield was $0.0007 \%$ of the original fruits in weight basis.

The following compounds were isolated; ethyl alcohol, $n$-propyl alcohol, $n$-butyl alcohol, isobutyl alcohol, $n$-amyl alcohol, (-)-2-methyl butanol, $n$-hexyl alcohol, hexene-3-ol, $n$-propyl acetate, $n$-butyl acetate, $n$-amyl acetate, $n$-hexyl acetate, ethyl caproate, formaldehyde, acetaldehyde, $n$-propionaldehyde, $n$-butyraldehyde, 2 -hexenal, nonyl aldehyde, isovaleric acid, caproic acid, benzoic acid, and an unknown $\alpha, \beta$-unsaturated acid.
\end{abstract}

\section{INTRODUCTION}

Numbers of investigations have been made about aroma constituents of apples since 1920. Power and Chesnut ${ }^{1)}$ found amyl esters of formic, acetic, caproic, caprylic acids and considerable portion of acetaldehyde, traces of methyl alcohol, ethyl alcohol, and formic, acetic, caproic acids in several varieties. Later ${ }^{2)}$, they reported the presence of geraniol in McIntosh apples.

The improvement of chromatographic technique and of recovering process of flavour constituents from fruit juice brought about the progress of these studies. White ${ }^{3)}$ identified acetaldehyde, acetone, hexyl aldehyde, furfural, 2-hexenal, methyl alcohol, ethyl alcohol, $n$-propyl alcohol, isopropyl alcohol, $n$-butyl alcohol, 2-methyl butanol, hexyl alcohol, and methyl, ethyl, isopropyl, $n$-butyl esters of formic, acetic, propionic, butyric acids from the mixture of McIntosh and Stayman Winsap apples. Thompson ${ }^{4)}$ found

1) F.B. Power and V.K. Chesenut, J. Am. Chem. Soc., 42, 1509 $(1920)$.

2) F.B. Power and V.K. Chesnut, ibid., 44, 2938 (1922).

3) J.W. White, Jr., Food Research, 15, 68 (1950).

4) A.R. Thompson, Aust. J. Sci. Res., B, 4, 289 (1951). methyl and ethyl esters of formic, acetic, valeric, caproic acids in Granny Smith apples.

Present work concerns with aroma constituents of commercial apple flavour essence*1) which was obtained from "KOGYOKU" apples*2) at Aomoriken Kaju Co., Ltd. by the use of recovery unit. The essence has a fine fresh apple aroma, and the concentration was 150 fold.

\section{EXPERIMENTAL AND RESULTS}

A total of $21.7 \mathrm{~kg}$ of apple flavour essence was saturated with ammonium sulfate and extracted three times with ether (total $4.5 \mathrm{l}$ ). Upon treatment of the aqueous layer with 2,4-dinitrophenylhydrazine, $8 \mathrm{~g}$ of the hydrazone was obtained. The ethereal extracts were combined and washed three times with sodium carbonate solution. A small amount of a mixture of volatile acids was recovered from sodium carbonate solution. The ethereal extract was concentrated by fractional

\footnotetext{
*1) According to the information from the factory, this specimen is quite rree from any additive compounds.

2*) "KOGYOKU" is one of the most popular species in our country which corresponds to American Jonathan apples, transplanted to Japan in about 1872 .
} 
distillation and the residue was dissolved in a small amount of $n$-pentane. The pentane solution was extracted three times with water to remove water-soluble alcohols. After removal of pentane, $23 \mathrm{~g}$ of apple oil was obtained. The yield was $0.0007 \%$ of the original fruits. The procedures described above are summarized in Diagram 1.

Neutral oil was fractionally distilled by means of Podbielniak's $8 \mathrm{~mm} \times 12$ inch HeliGrid column under reduced pressure. Ten fractions were collected and the residue was steam distilled to recover volatile substances. The results were summarized in Table $I$.

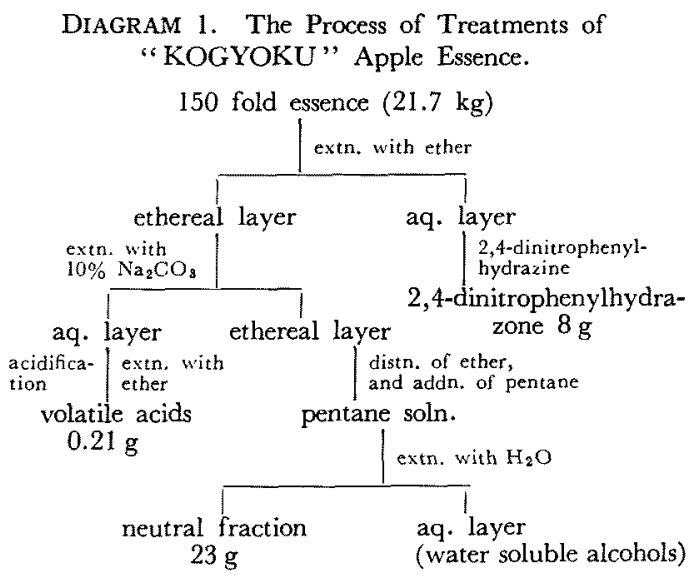

TABLE I. Fraction of the NeUtral APPle OIL

$\begin{array}{ccc}\begin{array}{c}\text { Fraction } \\ \text { No. }\end{array} & \begin{array}{c}\text { Volume } \\ \text { ml. }\end{array} & \begin{array}{c}\text { Calcd. b.p } \\ (760 \mathrm{~mm})\end{array} \\ \text { Cold trap condensate } & 3.0 & - \\ 1 & 1.0 & 103 \sim 109 \\ 2 & 1.0 & 109 \sim 113 \\ 3 & 2.0 & 113 \sim 115 \\ 4 & 1.0 & 115 \sim 124 \\ 5 & 1.0 & 124 \sim 127 \\ 6 & 1.0 & 127 \\ 7 & 1.0 & 127 \sim 138 \\ 8 & 1.0 & 138 \sim 143 \\ 9 & 1.0 & 143 \sim 144 \\ 10 & 0.5 & 144 \sim 147 \\ \text { Steam-distd. } & 1.8 & - \\ \text { fraction } & 4.5 & - \\ \text { Residue } & & \end{array}$

Analyses were carried out by the use Shimadzu's GC-2B type gas chromatograp The column materials were polyethyle glycol-celite and silicon grease-celite.

The composition of each fraction was e amined at first by referring to the IR spe trum and the retention time of the two se of gas chromatography by the use of the th sorts of column material described abov The fractions which seemed to contain ar esters were saponified with the mixture ( ethylene glycol, water and potassium hydro ide $(6: 1: 1)$. By referring to gas chromat grams of both samples, before and aft hydrolyses, final estimation of each esters w: attained. Owing to the rather complicate compositions of fraction $8,9,10$ and of th parts recovered from the distillation residu column chromatographic separation was at plied to these fractions by using Mallinct rodt's silicic acid as the adsorbent and $r$ hexane solution of ether $(3 \%, 5 \%, 10 \%$ $30 \%$ ) as the elution solvent. Each fractio thus obtained was followed by the analyse mentioned above.

It was found that both cold trap condensat and fraction 1 consisted of isobutyl alcohol $n$-butyl alcohol, $n$-propyl acetate, and $n$-buty acetate. The gas chromatograms of trap con densate, before and after hydrolyses, wer shown in Fig. 1. Column chromatograph was not practical for these fractions becaus! of their high volatility.

Fractions from 2 to 5 contained $n$-buty alcohol, (-)-2-methyl butanol and n-buty acetate.

Fractions 6 and 7 was ( - )-2-methyl butano in pure state. Fraction 8 was a mixture o (-) -2-methyl butanol, $n$-amyl alcohol, $n$ hexyl alcohol, hexene-3-ol, ethyl caproate, anc hexyl acetate. From fractions 9, 10 anc steam-distilled fraction, hexyl alcohol anc small amount of hexene-3-ol were isolated. 

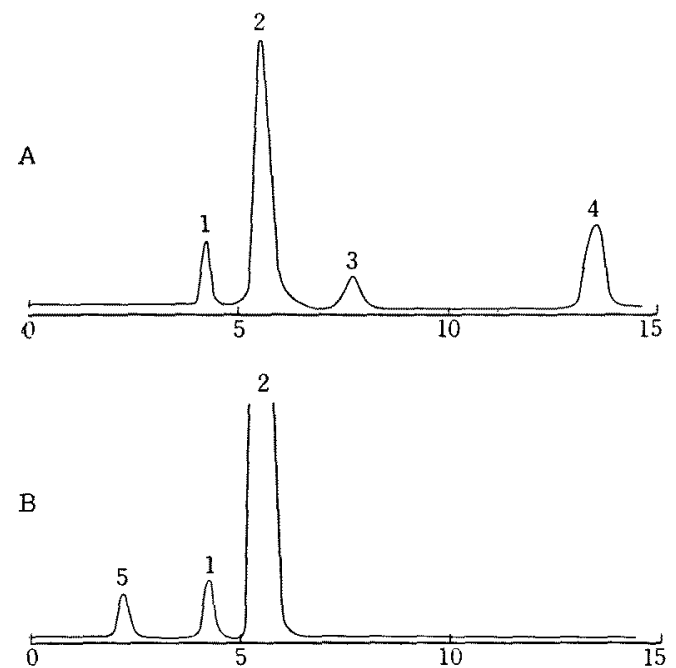

FIG. 1. The Gas Chromatogram of Trap Condensate.

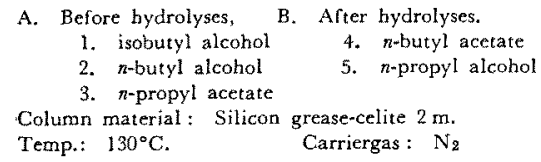

The retention time in gas chromatography*3) these compounds are: $n$-butyl alcohol, 5.4; (-) -2-methyl butanol, 6.0; $n$ butyl acetate, $4.9 ; n$-amyl alcohol, $7.5 ; n$ hexyl alcohol, 9.0; hexene-3-ol, 10.1; $n$-hexyl acetate, 7.5; ethyl caproate, 6.8 .

The precipitates of 2,4-dinitrophenylhydrazones from aqueous layer after ethereal extraction of the essence were subjected to column chromatography on silicic acid. As the developing solvent, the mixture of ether and $n$-hexane was used in the ratio $1: 9$ at the beginning and then $3: 7$. Each adsorption zone developed on the column was scrubbed out separately with long spatula and eluted out with ether. Analyses were carried out by means of paper chromatography using filter papers pregnated with N,N-dimethyl formamide as the stationary phase and cyclohexane saturated with $\mathrm{N}, \mathrm{N}$-dimethyl formamide as the mobile phase. Further identification of

3*) Column material, polyethylene glycol-celite; temperature, $130^{\circ} \mathrm{C}$.
TABLE II. THE Fractions OF THE COLUMN CHROMATOGRAPHY OF 2,4-DINITROPHENYLHYDRAZONE

Fraction Weight 2,4-dinitrophenyl- Methods of

1 trace nonyl aldehyde $\left\{\right.$ m.p. $95^{\circ} \mathrm{C}$

1 trace nonyl aldehyde $\left\{\begin{array}{l}\text { m.p. } 95^{\circ} \mathrm{C} \\ \text { (mixed m.p. } 96^{\circ} \mathrm{C} \text { ) }\end{array}\right.$

20.10 2-hexenal $\quad\left\{\right.$ m.p. $147^{\circ} \mathrm{C}$

(acetaldehyde $\quad\left\{\begin{array}{l}\text { (mixed m.p. } 147^{\circ} \mathrm{C} \text { ) } \\ R_{r}=0.39\end{array}\right.$

$30.42 \begin{cases}\text { acetaldehyde } & R_{F}=0.39 \\ n \text {-propyl aldehyde } & R=0.56\end{cases}$

n-butyraldehyde $\quad R_{F}=0.73$

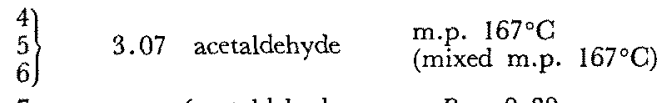

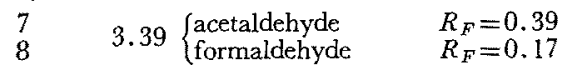

some compounds isolated in pure state was attained by measuring the mixed melting points with authentic samples. The results of chromatography was shown in Table II.

The aqueous layer extracted from pentane solution as mentioned before was fractionally distilled under atmospheric pressure until the distillate was free from organic materials. Five fractions were collected and analyzed by gas chromatography after being dried with potassium carbonate. The composition of each fraction was shown in Table III.

TABle III, The Composition of Distilled FraCTION OF AQUEOUS LAYER

\begin{tabular}{|c|c|c|c|c|}
\hline $\begin{array}{l}\text { Fraction } \\
\text { No. }\end{array}$ & $\begin{array}{l}\text { Volume } \\
\mathrm{ml} .\end{array}$ & $\begin{array}{l}=\text { Temp. } \\
\left({ }^{\circ} \mathrm{C}\right)\end{array}$ & Compounds & $\begin{array}{l}\text { Methods of } \\
\text { identification }\end{array}$ \\
\hline 1 & 0.5 & $60 \sim 85$ & $\left\{\begin{array}{l}\text { ethyl alcohol } \\
n \text {-propyl alcohol }\end{array}\right.$ & $\begin{array}{ll}\mathrm{GLC}, & \mathrm{R}_{\mathrm{T}}=3.2 \\
\mathrm{R}_{\mathrm{T}}=5.9\end{array}$ \\
\hline 2 & 1.3 & 85 & $\left\{\begin{array}{l}n \text {-propyl alcohol } \\
\text { isobutyl alcohol } \\
n \text {-butyl alcohol }\end{array}\right.$ & $\begin{array}{l}\mathrm{R}_{\mathrm{T}}=5.9 \\
\mathrm{R}_{\mathrm{T}}=8.5 \\
\mathrm{R}_{\mathrm{T}}=10.8\end{array}$ \\
\hline 3 & 1.0 & $85 \sim 91$ & n-butyl alcohol & $\mathrm{R}_{\mathrm{T}}=10.8$ \\
\hline 4 & 1.7 & 98 & $\left\{\begin{array}{l}n \text {-butyl alcohol } \\
\text { isoamyl alcohol }\end{array}\right.$ & $\begin{array}{l}\mathrm{R}_{\mathrm{T}}=10.8 \\
\mathrm{R}_{\mathrm{T}}=17.5\end{array}$ \\
\hline 5 & 0.6 & $98 \sim 99$ & $\left\{\begin{array}{l}n \text {-butyl alcohol } \\
\text { isoamyl alcohol }\end{array}\right.$ & $\begin{array}{l}\mathrm{R}_{\mathrm{T}}=10.8 \\
\mathrm{R}_{\mathrm{T}}=17.5\end{array}$ \\
\hline
\end{tabular}

A mixture of volatile acids recovered from aqueous sodium carbonate solution was esterified with ethyl alcohol and sulfuric acid which was followed by chromatography on silicic acid. Esters of isovaleric, caproic, benzoic acids, and an unknown fatty acid whose IR 
spectrum showed the presence of ethylenic linkage conjuated to carbonyl groups $(\mathrm{C}=\mathrm{C}$ $6.02 \mu, \mathrm{C}=\mathrm{O} 5.91 \mu$ ) were separated.

TABLE IV. COMPOUNDS IDENTIFIED FROM "KOGYOKU" APPLES

\section{Compound}

ethyl alcohol

$n$-propyl alcohol

$n$-butyl alcohol

isobutyl alcohol

$n$-almyl alcohol

(-)-2-methyl butanol

$n$-hexyl alcohol

hexen-3-ol-1

$n$-propyl acetate

$n$-butyl acetate

$n$-amyl acetate

$n$-hexyl acetate

ethyl caproate

formaldehyde

acetaldehyde

$n$-propionaldehyde

2-hexenal

nonyl aldehyde

$n$-butyraldehyde

isovaleric acid

caproic acid

benzoic acid

$\alpha, \beta$-unsaturated acid g. in $21.7 \mathrm{~kg}$. natural flavour essence

0.3

1.0

8.4

0.7

0.1

4.1

2.5

0.2

0.2

2.0

0.6

0.2

$+$

0.4

1. 8

0.1

0. 1

$+$

$+$

0.2

0.8

0.8

0.3
Results are summarized in Table IV. The estimation of the quantity of each component was attained by weighing the is lated fraction, as far as possible, and $\mathrm{t}$ calculating the peak area of gas chromatogras of further inseparable intermediate fraction

It is rather difficult to separate 2-meth butanol from isoamyl alcohol owing to clo: similarities of their boiling points and $\mathrm{g}$ : chromatographic retention time; isoamyl a cohol fraction of apple essential oil is eviden ly composed of almost pure 2-methyl butano taking into account the value of its optici rotation, $\left.[a]_{18}^{D}=-5.42 * 4\right)$.

In general, much different aroma are note among species of apples. Proportion of voli tile constituents, especially, of esters in ou specimen is rather different from the on reported regarding the foreign varieties. A shown in Table IV, the aroma of "KOGYC KU" apples is thought to be contributer mainly by the presence of esters of $n$-propy] $n$-butyl, $n$-amyl and $n$-hexyl alcohols. Th combination of these compounds listed abov was found insufficient to reconstruct the fin aroma of "KOGYOKU" apple. This fac suggests the presence of some unidentifie compounds which are essential to the arom. of fresh apples and the study of which wil need far more expense and labour owing to their extremely minute quantities. 